\title{
The Students' practical innovative ability Based on Engineering Training Center
}

\author{
Lianhai Yuan ${ }^{a}$, Huachun Liu ${ }^{b}$ Xiangwen $\mathrm{Li}^{\mathrm{c}}$ \\ Departent of Electronic information and Computer Engineering The Engineering \&technical College \\ of Chengdu University of Technology Leshan, China \\ ayuanlianhai72@qq.com, biuhuachun@163.com, 'ixw@cdutetc.cn
}

Keywords: practical teaching reform; engineering training center; independent colleges; innovative ability.

\begin{abstract}
This paper introduces practical teaching reforms in engineering training center. To achieve the purpose of building engineering training center, We do many works ,includes hardware construction, teaching team building, practical teaching system reform, practical course construction ,building experiment manual and exemplary engineering training courses construction .through these works, We achieved good teaching effectiveness. Many students achieve good ranking in academic competition, Learning efficiency has greatly improved.
\end{abstract}

\section{Introduction}

The Engineering \&technical College of Chengdu University of Technology is considered as an experimental teaching demonstration center (i.e. engineering training center) construction unit by the education department of Sichuan provincial in 2009.The purpose of building engineering training center is to improve the quality of the training of students, vigorously carry out engineering education, training market integration of application-oriented, innovative engineering and technical student, and provide social services for the local economy, sustainable development road running.

To achieve these goals, the college established the building concept of the engineering training center: emphasis on production processes of modern Enterprise , build a mechanical and electrical specialties and other specialty groups of related disciplines, multi-level engineering training curriculum for students in a real business scenario teaching environment, and carry out engineering capability training and comprehensive innovation training, and improve the application of innovation and student training quality, enhance teachers' practical teaching ability and innovation ability, to achieve teaching, research and production promote each other.

\section{Engineering training center main practical teaching reform}

The fundamental purpose of building engineering training center is comprehensively improving innovation ability and talent training quality. Teachers' practical teaching ability and innovation capability is the fundamental guarantee for achieving the above object. Under the guidance of the experts Steering Committee in engineering training center, engineering training center established a general line, comprehensive to improve innovation ability and talent training quality technical namely, strengthening engineering training center hardware platform, vigorously carry out practical teaching system reform based on the context of large projects, the construction of practical courses, and practical courses related practical manual, to create a practical teaching team with innovative capability for local and regional economic development, continuous supply application-oriented, innovative engineering and technical professionals. The reforms are as follows:

Strengthen the construction of engineering training center platform. To cultivate applied, innovative engineering and technical professionals, we must take right education and teaching concept. Cultivating applied engineering and technical talent is college personnel cultivating objectives. This cannot do without engineering education. Ten years of school experience tells us that the best way to carry out engineering education is to build a powerful engineering training center, 
build a practical teaching ability of excellent teaching team. Left the engineering training center this hardware platform, then good practical teaching team is also difficult to play its educating people skills. This hardware platform for the training of the application on the one hand, innovative engineering and technical personnel to provide a good hardware teaching conditions, but also become a faculty practical teaching to enhance the ability of hospital training base. Center to enhance practical teaching ability of teachers in turn enhance the innovative ability. Therefore, construction of engineering training center of the platform becomes essential.

How to make good use of this platform to enhance students' practical ability and creative ability; how to build a practical teaching ability excellent teaching team, how to innovate in order to highlight the students to carry out engineering practice and innovative ability for the main purpose of the practical teaching curriculum construction and the corresponding practical manual construction; and how central platform in production, learning and research aspects of the unique advantages to promote students' practical ability and innovation capability, all this is our next major work.

Strengthen practical teaching team building.Cultivate applied, innovative engineering talent is our training objectives. From the beginning of school, the College has recognized the extent of the goals of engineering practice and professional level of teachers' comprehensive quality and professional closely; without an engineering practical ability, excellent practical teaching team, college is not may foster applications, innovative engineering and technical personnel. Therefore, to enhance teachers' practical teaching ability, strengthen teaching practical team building became sure of applied oriented, innovative engineering and technical quality of the training of key initiatives.

Ability to build an excellent practical teaching team is the center of a long-term and arduous task. We seek government support and the broad participation of enterprises, in particular, to mobilize the enthusiasm of the teachers center and initiative, active participation in the production and social practice, and constantly improve the overall quality of the majority of teachers' professional and practical teaching ability, better economic and social development to train more and better innovative applied engineering and technical personnel.

Deepening practical teaching system reform.As features of independent college, we have been taken from the beginning of creation of hardware and software construction. We both learn advanced concepts and reform the existing practical teaching system. Continue to explore the characteristics for the independent college students' practical teaching rule, namely: reform of practical teaching system must be suited to application-oriented, innovative engineering and technical personnel training objectives. In the dark, we will focus on the reform of teaching content to carry out practice, practical teaching methods, and methods of reform, the professional practical curriculum system reform and practical teaching management system construction and so on. On the one hand, teachers take part in education reform, in continuous learning and innovation to enhance teachers' practical teaching ability; on the other hand we reformed the new system will be more conducive to the practice of teaching college application oriented, innovative engineering and technical personnel training. We made the following aspects of the reform.

- practical teaching content;

- practical teaching methods;

- teaching course system.

Practical course construction and building experiment manual.The world has entered the information age, the rapid development of modern science and technology, knowledge, unprecedented growth and update rate to accelerate. According to statistics, today's new technological knowledge 3-5 years increased by 1 times the half-life of knowledge is only three short years. In this situation, under the ultimate goal of education should be to lay a solid foundation, capacity (the ability should include knowledge acquisition capabilities, engineering practice, integrated innovation, etc.), development potential. Engineering training center is to provide students with the ability. With a central practical teaching system reform, to highlight the ability of students, especially students ability to innovate practical course construction is bound to become the center of all teachers need to explore. Specific technical route is as follows: 
1) To establish a scientific system of curriculum goals: construction of university courses task is reasonably effective in teaching all aspects of the whole process to enrich, improve, additions and amendments. This requires a complete curriculum goals feasible and reasonable system.

2) Optimization course content with students' innovative ability as objective. Traditional teaching content is often lags behind the development of technology. Just past the old knowledge with training for future service personnel which in itself is a contradiction, let alone to cultivate students' creative ability? We can try to core courses in the professional application of theoretical knowledge through close contact with the Project, to solve practical problems from the theory of teaching. Meanwhile, we can also more teaching content to students leaving space to think, it is easier to stimulate students' creative thinking. In particular, we can put teachers and students in research projects combined curriculum knowledge, on the one hand enable students to experience the forefront of profound knowledge, on the other students' innovative spirit.

3) Teaching experiment to achieve the transformation of experimental teaching. In the past teaching experiments is mainly theoretical teaching and experimental teaching is auxiliary, while training applied, innovative engineering and technical personnel more requirements on the use of knowledge and talent based on the original innovation. Therefore, this experimental teaching as the main teaching method is perfect for college personnel training objectives. College dean and center advocated theoretical courses into the laboratory of this new way of teaching. This change in the way teaching undoubtedly will involve the construction of practical courses. It will include the resulting practical course syllabus revision, practical writing curriculum materials, professional practical curriculum system construction and much more.

Construction a number of exemplary engineering training courses.Excellent course construction is an important part of higher education quality course construction. Engineering training center is to culture applications, innovative engineering and technical personnel, we must build a high level of practical courses, with high quality engineering training courses driven professional development, enhance the innovative capability. Such as "electronics design and technology", the current provincial excellent quality courses under construction, the construction of this course is in line with the teaching experiment to experiment teaching, changes will be translated into practical theoretical courses to train more students in the professional engineering practice and innovative ability. Our specialty is to take this into the core curriculum areas of the construction of quality courses go, the students' practical ability and creative ability to better implement the curriculum construction go.

\section{Industry, academia, research combining students' practical innovation capability}

Practice teaching is important to cultivate students' innovative spirit and practical ability, and is an important way to cultivate applied talent. To ensure the quality and level of practice teaching to enhance students' ability to innovate and employment competitiveness, we full use of social resources, and opened the road of cooperative education. Initially confined to the school-enterprise cooperation students practice base construction, the reason is that the device used in school update lower than enterprise. Engineering training center is to meet the mastery of general rule, teaching innovation requires more intuitive feelings. And this feeling only the enterprises can provide teachers and students. Preliminary school-enterprise cooperation in the training to make college application oriented, innovative engineering and technical talents tasted the sweetness. School-enterprise cooperation to further expand the scope of research must walk the path of integration. Because school trained people must first be accepted by businesses, students are unable to employment how to talk about innovation? We strengthen research study from the following aspects:

1) We introduced a series of encouraging and supporting research cooperation policies and institutions to encourage teachers to enter the enterprise to participate in production, scientific research, product promotion, services and other practice. Enterprises through college personnel support for technological innovation, can improve their own products in the industry's competitiveness; faculty through participation in different levels of practice and research activities 
can be separated from the theory and practice to overcome the shortcomings, and thus improve their academic level and practical teaching ability. Teachers with excellent practice teaching are possible to cultivate a high-quality application-oriented, innovative engineering and technical personnel. Therefore, the relevant policies and institutions to encourage the introduction are quite necessary.

2) At the College policy within the allowable range to establish a long-term mechanism research. To maintain stable relations research cooperation, so that the healthy development, we must establish a long-term mechanism. This mechanism is based on the characteristics of social demand for the guide, the center for the industry initiative and enterprise services, such as: for enterprises to develop job training staff, providing intellectual support, etc; industry enterprises to actively participate in school running, such as: Business become a college campus training base, employment counterparts, exists between schools and enterprises mutually beneficial relationship. The persistence of this relationship, more conducive to innovation and continuity of personnel training, making college personnel training and social enterprise is always seamless.

3) The construction of the center in the curriculum to promote CDIO engineering education law, and teachers in the school-enterprise cooperation in research is the best approach to education teaching carrier. This could narrow the distance between students and engineering applications, for students to create a wider space of thinking, and their resulting burst of creative inspiration, and their spirit of innovation in teaching practice to get training, time and again their ability to innovate and get promoted.

\section{Summary}

In order to cultivate innovative, application-oriented student, we established the engineering training center. Reforms in the center are several aspects: 1) strengthen the construction of engineering training center platform;2) strengthen practice teaching team building;3)deepening practice teaching system reform practice course construction and building experiment manual 4)construction a number of exemplary engineering training courses. We also do lots of work on regional economy and industry combined industry, academia, and research combining students' practical innovation capability. Through several years of construction, engineering training center has developed into an important teaching practice teaching base in southern Sichuan. We achieved good practice teaching effectiveness. Trained a large number of innovative applications talents. Many students achieve good ranking in academic competition, Learning efficiency has greatly improved

\section{References}

[1] Information on http://etc.cdutetc.cn

[2] Zhi Chenghuang, inclusive Education - Focus on learning and participation of all students,” Shanghai Education Press. Shang Hai, 2004,pp. 30-60.

[3] Kun Jinbao, the revelation for reform of vocational education in our country from human nature assumption of inclusive education, Jiangsu Agricultural and forestry vocational technical collegeJournal. Nan Jing: January 2006, pp. 21-24.

[4] Xin Yihou, higher vovational education and teaching under the theory of inclusive education,” Eduacion and Vocation.Bei Jing: May 2007,pp.172-173 